Revista Vernáculo, nº 11-12-13, pp. 49 - 60.

\title{
Filmes “Sessão da Tarde”: O clube dos Cinco e seu lugar histórico na cinematografia.
}

\author{
César O. Cundari da Rocha Santos ${ }^{1}$
}

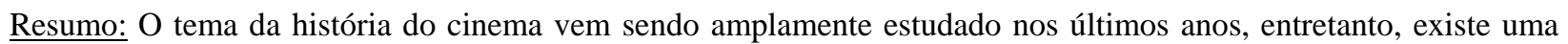
pequena lacuna: o cinema entretenimento característico dos anos oitenta e direcionado a um público jovem/adolescente. É este tipo específico de filme o tema central desta pesquisa. Torna-se claro, que boa parte deste novo fazer cinematográfico estava ligado a um novo pensar artístico, tão comum a movimentos estéticos, como a Pop Art. Para entender a dinâmica entre estes filmes puramente entretenimento direcionado a um público bem específico, se procurou fazer uma analise fílmica de um dos filmes que representassem o "cinema sessão da tarde". Trata-se do clássico filmes de John Hughes "O Clube dos Cinco". Além disto, a História do cinema, tem demonstrado que este tipo de filme acaba por se articular com outros tantos e que chega mesmo a remontar ao cinema de auter da Nouvelle Vague cinematográfica francesa. É em meio a estes característicos sistemas de filmagem que esta pesquisa pretende localizar em um lugar histórico especifico, o cinema "pós-moderno".

Palavras-chave: História, cinema, cinema norte-americano.

Hoje é comum encontrarmos uma designação peculiar, um gênero cinematográfico cotidianamente conhecido como "filmes sessão da tarde". Este programa tinha uma espécie de identidade que foi capaz de transformar o nome deste programa em um "adjetivo", algo que era comum a este tipo específico de filme².

Todos estes novos "signos" no fazer artístico tinham por objetivo atingir um novo tipo de público, um público especializado. No caso especifico do "Filme Sessão da Tarde”, tratava-se do público jovem.

Assim, é proposta desta pesquisa demonstrar de que forma estes filmes, tão comumente mal vistos por críticos e pseudocríticos, não somente fazem parte de um movimento artístico/cinematográfico que revolucionou o modo de se fazer cinema em Hollywood (berço do cinema mundial), mas também demonstrar que este movimento em nada estava desarticulado ao que se propunham para sua época.

\section{Pós-modernidade e instituição cinematográfica.}

No primeiro capítulo do interessante livro "Compreender o Cinema”, de Antonio Costa, este faz uma discussão sobre "instituição, dispositivo e linguagem". Neste capítulo, o escritor consegue dar um exemplo dos mais propícios sobre como se pode enxergar a "instituição" cinematográfica. Citando um filme de Elias Kazan, O ultimo magnata, baseado em um romance de F. Scott Fitzgerald, ele descreve uma cena entre dois personagens, um produtor de cinema e um roteirista com problemas para "entender o que devia ser feito":

Stahr: no escritório tem uma lareira que se acende com um fósforo?

Boxley: acho que sim.

Stahr: imagine estar em seu escritório (...) está morto de cansado. Este é o senhor. Há uma mulher na porta. Entra e não o vê. Tira as luvas. Abre a bolsa e a esvazia em cima da mesa. O senhor a olha. Este é o senhor. Agora ... A mulher tem dois centavos, fósforos e um níquel. Deixa o níquel em cima da mesa, volta a pôr os dois centavos na bolsa. Depois apanha as luvas, são negras. Coloca-as sobre a lareira. Acende um fósforo. Soa o telefone ... Levanta o fone. Escuta. Ela diz: "nunca tive um par de luvas negras na vida". Desliga. Ajoelha-se perto da lareira, acende outro fósforo. De repente o senhor se dá conta de que há um outro homem na sala. Um homem que está observando cada movimento que faz a mulher.

(Longa pausa.).

Boxley: O que acontece depois?

Stahr: Não sei! Eu estava só fazendo cinema.

\footnotetext{
${ }^{1}$ Graduando em História UFPR

${ }^{2}$ Ainda hoje é comum encontrarmos esta definição em resenhas de jornal e em sites de internet. N. A.
} 
Boxley: O níquel, para que era?

Stahr: (Voltado para uma colega de Boxley que assiste a cena) Jenny, você sabe pra que servia o níquel?

Jenny: Servia para fazer cinema. ${ }^{3}$

Boxley: Mas você me paga pra fazer o quê? Não entendo estas estórias estranhas.

Stahr: Entende sim. Senão não me teria perguntado a respeito do níquel. ${ }^{4}$

Torna-se óbvio que, apesar dos exageros característicos do gênero, esta cena é muito esclarecedora sobre o "fazer cinema”. Ele, De Niro/Stahr, de forma subjetiva, nos indica não só papel do personagem Boxley no seu trabalho de roteirista, mas também a nossa posição como espectadores, nos dois sentidos possíveis, no econômico, com o níquel que "servia para você ir ao cinema", ou no sentido de voyeur, indicado pela presença não vista do personagem Boxley.

Segundo Metz, o cinema tem uma via de mão dupla para conosco. Esta afirmativa trás em si toda uma discussão sobre as relações entre o ver e o ser visto inerentes ao processo, não só material do filme, mas também simbólico. Em suas palavras, esta relação se dá da seguinte forma: "O exibido sabe que é olhado, outra coisa não deseja, se identifica com o voyeur, para quem ele é objeto (mas que também o constitui como sujeito). (...) o filme não é exibicionista. Eu olho para ele, mas não ele para mim a olhá-lo. Contudo, sabe que o olho. Mas faz que não sabe" . E conclui mais adiante, "quem sabe é o cinema, a instituição (e sua presença em todos os filmes, ou seja, o discurso sob a história); quem faz que não sabe é o filme, o texto (o texto terminal): a história”. ${ }^{6}$

Outra situação interessante é o papel da instituição, em Metz na figura do "cinema” e em Costa na figura de Sathr, e o papel do espectador, ou seja, aquele que não somente vê o filme, mas que também paga o seu níquel por isso. Esta relação tão presente entre o cinema, o filme, e a compra deste filme, é um dos principais enfoques para a conturbada relação entre cinema e indústria, mas acima de tudo entre arte e consumo de massa.

Na cena de Kazan, esta relação se dá de forma quase que direta, já que parece que a instituição (De Niro) tem uma única função, a de fazer com que o espectador (Boxley) continue a manter-se atento e gaste seu níquel, "Boxley se deixa levar pela sedução de Stahr, como nós pela de De Niro"7. Este "níquel”, a tempos vem sendo apontado como a causa do declínio da qualidade do cinema em geral.

Entretanto, a par e passo com esta discussão, também se encontram as constatações feitas por Robert Sklar, que afirma que o cinema vinha sofrendo declínio de publico e renda (relativa) desde o pós-guerra. Para ele, o motivo para este declínio se encontrava em diversos fatores (estes temas serão mais propriamente abordados no capítulo dois). A alternativa criada pelos executivos de Los Angeles foi a de tornar os filmes cada vez mais atraentes para 0 maior número de pessoas, além de relativamente mais baratos e feitos em menor número. Segundo Sklar, o cinema passou a apostar não mais em fórmulas feitas, como era o caso nas décadas de 20,30 e 40. Isto fez com que a industria hollywoodiana então começasse a apostar em um crescente mercado, o dos jovens ${ }^{8}$. Estes, por sua vez, tinham interesse específico em coisas tal como violência, sexo e Rock’n’Roll, temas provenientes da "baixa cultura", ou cultura popular.

Segundo Christopher Vogler, é possível chegar a um pressuposto simples: "todas as histórias consistem em alguns elementos estruturais comuns, encontrados universalmente em mitos, contos de fada, sonhos e filmes”. A partir disto todos os personagens da trama, sejam os positivos, sejam os negativos, passa uma espécie de "Jornada do Herói”, que também, não por acaso, trata-se do nome de seu livro. Entrementes, nem todos os personagens fazem parte de um mesmo grupo, ele divide seus arquétipos em sete grupos - o Herói, o Mentor, o Guardião do Limiar, o Arauto, o Camaleão, a Sombra e o Pícaro. No entanto, também é necessário que se diga que os personagens não são

\footnotetext{
${ }^{3}$ Segundo Costa, na versão original esta frase seria ainda mais interessante, e seria transcrita desta forma: “Ah sim ... o níquel servia para ir ao cinema”. COSTA, Antonio. Compreender o cinema. São Paulo: Globo, 2003. Pág.22.

${ }^{4}$ Id. Ibid. Pág. 21-22.

${ }^{5}$ METZ, Christian. Historia/ Discurso (notas sobre dois voyeurismos). In: XAVIER, Ismail (Org.). A experiência do cinema: antologia. Rio de Janeiro: Editora Graal, 1983. Pág. 407.

${ }^{6}$ Id. Ibid.

${ }^{7}$ COSTA, Antonio. Compreender o cinema. São Paulo: Globo, 2003. Pág.25.

8 "os filhos do boom de bebês ocorrido depois da guerra”. SKLAR, Robert. História social do cinema americano. São Paulo: Ed. Cultrix, 1975. Pág. 349-350.

${ }^{9}$ Sobre o tema ler: GANS, Herbert J. Popular Culture and High Culture: an analisys an evaluation of taste. New York: Basic Books, 1974.
} 
estáticos em seus arquétipos. Na verdade, é bem comum, e mesmo interessante, que um personagem passe, durante todo o filme, por vários arquétipos diferentes ${ }^{10}$.

É inegável o direcionamento do produto artístico para uma padronização ${ }^{11}$, entretanto, é também inegável a natureza de massa de produtos concebidos ante a era da reprodutibilidade. Neste instante, a arte podia facilmente chegar a dezenas de milhares de pessoas em diversas localidades do globo. Walter Benjamin soube notar a vocação do cinema como a arte central do século, em grande parte por conta de suas qualidades reprodutivas, ou seja, ele considerava que por conta de sua reprodutibilidade a arte poderia alcançar um maior número de pessoas e, por conseqüência, interessar a um maior número de pessoas.

Adorno por sua vez, vê nesta reprodutibilidade algo nocivo às artes, segundo ele ao visarem à produção em série a homogeneização seria inevitável e, como conseqüência disto, as técnicas ${ }^{12}$ de reprodução sacrificariam a distinção entre o caráter da própria obra de arte e do sistema social. ${ }^{13}$

Além disto, também torna-se claro que esta crítica baseia-se em "on a skewed comparison, with the best features of the past compared to the worst of the present".${ }^{14}$ É muito fácil comparar W. Shakespeare com Paulo Coelho, ou Beethoven com Charlie Brown Jr.

Segundo Featherstone, esta mudança encontra-se no centro de uma mudança muito mais ampla chamada pós-modernidade. Para ele as principais características deste pós-modernismo nas artes são: “a abolição da fronteira entre arte a vida cotidiana; a derrocada da distinção hierárquica entre alta-cultura e cultura de massa/popular; uma promiscuidade estilística, favorecendo o ecletismo e a mistura de códigos; paródia, pastiche, ironia, diversão e a celebração da 'ausência de profundidade’ da cultura; o declínio da originalidade/genialidade do produtor artístico e a suposição de que a arte pode ser somente repetição". 15 Torna-se claro que esta nova forma de se encarar o mundo tratava-se de uma exacerbação do modernismo, onde "o instintivo e o prazer liberados para levar a lógica modernista a suas últimas conseqüências”. ${ }^{16}$ Além disto, esta noção de pós-modernidade poderia ser expandida para além da vida artística em geral.

Dentro da perspectiva do pós-modernismo, Featherstone identifica três formas fundamentais de cultura de consumo, onde a primeira poderia ser considerada uma expansão da produção capitalista de consumo, onde a mercantilização de bens culturais ganha grande importância. Em segundo lugar encontra-se a concepção de satisfação pela posse de bens, onde “a satisfação proporcionada pelos bens e seu acesso socialmente estruturado era é um jogo de soma zero”. ${ }^{17}$ E terceiro lugar, e mais interessante para a proposta desta pesquisa, o consumo para celebração de um desejo/sonho do imaginário cultural consumista. Esta premissa também pode ser encarada como

\footnotetext{
10 “Olhando os arquétipos desta maneira, como funções flexíveis de um personagem e não como tipo rígidos de personagens, é possível liberar a narrativa. Isso explica como um personagem numa história pode manifestar qualidades de mais de um arquétipo”. In: VOGLER, Christopher. A Jornada do Escritor: Estruturas míticas para contadores de histórias e roteiristas. Rio da Janeiro: Ampersand Ed., 1997. Pág. 49.

11 "That the mass culture is an industry organized for profit; that in order for this industry to be profitable, it must create a homogeneus and standartized product that appeals to a mass audience; and that this requires a process in which the industry transforms the creator into a worker on a mass productions assembly line, requiring him or her to give up the individual expression of his own skill and values”. GANS, Herbert J. Popular Culture and High Culture: an analisys an evaluation of taste. New York: Basic Books, 1974. Pág. 20.

${ }^{12}$ Esta pode ser definida em dois níveis: enquanto houver coisa determinada "intra-esteticamente” e "enquanto desenvolvimento exterior às obras de arte”. ADORNO, Theodor W. Textos Escolhidos. In.: Coleção os Pensadores. São Paulo: Ed. Nova Cultural Ltda, 1999.

13 “Ha nos escritos de Benjamin um forte veio populista, que é muitas vezes contrastado com o propalado elitismo de Horkheimer e Adorno. Benjamin Enfatizou o momento utópico, ou positivo, da produção de mercadorias para consumo em massa, que permitiu à criatividade se libertar da prisão da arte e migrar para a multiplicidade de objetos cotidianos produzidos em massa (fica evidente aqui a influência do surrealismo no arcabouço teórico de Benjamin)”. FEATHERSTONE, Mike. Cultura de consumo e Pós-modernidade. São Paulo: Studio Nobel, 1995. Pág. 44.

${ }^{14}$ GANS, Herbert J. Popular Culture and High Culture: an analisys an evaluation of taste. New York: Basic Books, 1974. Pág $44 / 45$.

${ }^{15}$ FEATHerstone, Mike. Cultura de consumo e Pós-modernidade. São Paulo: Studio Nobel, 1995. Pág. 25. Ver também RAMOS, José Mario Ortiz. Televisão, publicidade e cultura de massa. Petrópolis: Vozes, 1995. "O movimento acolhia provocativamente uma teenage culture, mergulhava uma visão positiva no universo contemporâneo, através de incorporação de procedimentos do cinema, publicidade e história em quadrinhos, da reelaboração de objeto do cotidiano, enfim, borrava fronteiras entre os planos ‘erudito’ e do ‘consumo de massa’”. Pág. 227.

${ }^{16}$ Id. Ibid. Pág. 26.

${ }^{17}$ FEATHERSTONE, Mike. Cultura de consumo e Pós-modernidade. São Paulo: Studio Nobel, 1995. Pág. 31.
} 
um "aspecto duplamente simbólico das mercadorias”, ${ }^{18}$ onde o simbólico não se evidencia somente na estética e no imaginário intrínseco, mas também na forma de distinção social que tal ou qual produto pode lhe render ${ }^{19}$.

Toda esta discussão leva a uma pergunta: com o estreitamento da distinção entre a vida cotidiana e a arte, o que aconteceria com esta? Sobre o assunto Baudrillard acrescenta: " $E$ assim a arte está por toda parte, uma vez que o artifício jaz no próprio coração da realidade. E assim a arte está morta, não somente porque sua transcendência crítica está perdida, mas porque a própria realidade, totalmente impregnada por uma estética inseparável de sua estrutura, vem sendo confundido com sua própria imagem”. ${ }^{20}$

A arte agora tinha nova cara e nova função. Não era mais estática e distante. Tudo agora tinha e era arte. Ela agora fazia muito mais parte do nosso dia-a-dia, nos identificava, socialmente, etnicamente, culturalmente e economicamente. Esta arte de agora tinha uma característica indispensável para tudo o que estaria por vir, ela era dessacralizada.

\section{Crise estrutural e conjetural, o cinema que nos antecede.}

Nos Estados Unidos do pós-guerra a história do cinema ganha um diferente aspecto. Hollywood enfrentava diversos desafios e crises. O congresso americano nunca havia intensificado tanto o cerco em volta dos cineastas, além disto. Isto sem mencionar que também era necessário um grande esforço para lidar com a crescente crise que se abatia no cinema americano.

E ao passo que o país prosperava, Hollywood não o imitou. (...) Depois de 1946, a freqüência e as receitas das bilheterias principiaram a cair, antes mesmo que a televisão produzisse seu significativo impacto por volta de 1949 ou 1950. Em 1953, quando se calculava que 46,2\% das famílias norte-americanas possuíam televisores, a assistência dos cinemas caíra para quase exatamente a metade do nível mais alto de 1946. Importa não esquecer, todavia, que Hollywood tinha problemas que teriam posto seriamente em cheque sua popularidade e sua capacidade de ganhar dinheiro ainda que a televisão nunca tivesse existido. ${ }^{21}$

Todo este cenário fez surgir o que é comumente chamado de "Cinema Moderno". Este cinema, que data principalmente de fins da década de cinqüenta, tem algumas peculiaridades:

(...) aquela que nos propusemos a chamar de cinema moderno é mais difícil de circunscrever e definir. (...) Não existe uma inovação tecnológica comparável a do cinema sonoro a ponto de modificar e unificar o estatuto da narração, como aconteceu entre os 20 e 30. Primeiro a introdução da cor e, depois a da tela panorâmica não têm efeitos suficientes para modificar o estatuto expressivo, tendo, no máximo, o efeito de reforçá-lo, uma vez que tais inovações têm o objetivo de limitar a emergente concorrência da televisão. ${ }^{22}$

A linguagem específica do cinema já tinha seus signos específicos.

"Desde de 1969, tem havido diversas modificações na indústria de filmes americana, mas a maioria delas têm apenas efeitos menores no modo de produção” (STEIGER, Janet). O “estilo”, por sua vez, vai sofrer, por exemplo, as influências do "cinema arte" dos anos 60. No entanto, o estilo clássico e os padrões fixados nas primeiras décadas permanecem como a referência, absorvendo inovações técnicas e de linguagem. ${ }^{23}$

Este "novo velho" cinema tinha grande influencia de diretores europeus, principalmente os franceses. A "nouvelle vague cinematográfica", tinha chegado com grande força e com um referencial teórico dos mais abalizados. Os "discípulos” de Bazin, de alguma forma recuperam o poder e prestígio do filme de auteur, assim recuperando quase que totalmente o controle do processo do fazer cinematográfico. Houve uma valorização do

\footnotetext{
${ }^{18}$ Id. Ibid. Pág. 35.

19 "Para Adorno, a dominância cada vez maior do valor de troca não somente suprimiu o valor de uso original das coisas e o substituiu pelo valor abstrato, como também deixou a mercadoria livre para adquirir um valor de uso ersatz ou secundário, o que Baudrillard posteriormente designaria como ‘valor signo’”. Id. Ibid. Pág. 100-101.

${ }^{20}$ BAUDRILLARD, Jean. Apud. In.: FEATHERSTONE, Mike. Cultura de consumo e Pós-modernidade. São Paulo: Studio Nobel, 1995. Pág. 102.

${ }^{21}$ SKLAR, Robert. História social do cinema americano. São Paulo: Ed. Cultrix, 1975. Pág. 316.

${ }^{22}$ COSTA, Antonio. Compreender o cinema. São Paulo: Globo, 2003. Pág. 114.

${ }^{23}$ RAMOS, José Mario Ortiz. Televisão, publicidade e cultura de massa. Petrópolis: Vozes, 1995. Pág.19.
} 
diretor-autor, das técnicas simples de produção. Esta escola francesa de cinema primava principalmente pelo espontâneo, pelo imediato, e tinha uma proposta de fazer cinema com um custo relativamente baixo. Estes novos diretores pregavam "um tipo de cinema pessoal”, a subjetividade do autor, mas principalmente a visão deste sobre o cinema. Estes novos diretores conheciam cinema como antes não se conhecia: "Nós somos os primeiros cineastas dizia orgulhosamente Godard no início dos anos 60 - a saber que Griffith existe"24.

Segundo Costa, utilizando-se da pesquisa de Miccichè, era possível sintetizar em quatro pontos as inovações desse movimento:

1. Estrutura narrativa: são abandonados os enredos "romanescos” e a construção da personagem acabada e são adotadas soluções mais próximas das novas tendências literárias;

2. Linguagem fílmica: abandono das formas sintáticas e expressivas tendentes a ocultar o procedimento de encenação, evidenciando assim a subjetividade do autor;

3. Ideologia: em vez de evidenciar uma mensagem ideológica unívoca e direta, geralmente confiada a um herói positivo, surgiram formas mais fluidas e indiretas, baseadas em procedimentos metafóricos e alegóricos;

4. Estruturas de produção: manifesta-se sempre uma exigência de mudança, mesmo que de formas muito distintas; ${ }^{25}$

Foi por meio desta vanguarda que o cinema entrou em contato com movimento da pop art.Este contato foi importante para esta nova vanguarda que buscava uma nova forma de se fazer o cinema. Entretanto, seu maior feito foi o de trazer a tona uma discussão em torno do sagrado no cinema. As bases continuavam as mesmas, mas neste instante era possível abrir mão de coisas que sempre pareceram fundamentais a expressão cinematográfica, tal como o exemplo da narrativa. "Nos anos 60 a idéia de renovação, de mudança que havia dominado o cinema moderno, pressupunha uma vitalidade e um desenvolvimento ilimitado da instituição cinematográfica" ${ }^{26}$.

Em fins da década de 60, estava claro que o cinema não mais poderia ser o mesmo. Os poucos filmes que haviam dado real lucro à indústria cinematográfica, foram não somente filmes despretensiosos, mas também filmes que enfocavam temas que eram pouco, ou quase nada, correntes ao cinema hollywoodiano padrão. Easy Ryder (1969) foi um exemplo concreto disto, tratava de temas que antes eram relegados ao cinema marginalizado. "De súbito, porém, a juventude ficou na moda" ${ }^{27}$ Este, assim como o grande sucesso de 1967, Bonnie e Clyde, deixava claro o tipo de cinema que os filhos do boom demográfico da década de 40 queriam assistir. À indústria, restavam poucas opções, ou o investimento se localizava neste modismo jovem ou teria que apelar para os chamados filmes $\mathrm{X}$.

Entretanto, parecia claro que a "política de autores", tão propagada pela novelle vague, deixava aberta a possibilidade de se estabelecer uma linha alternativa, uma linha que não fosse nem tão "niilista" e tão pouco fosse estacionária e temerosa de inovações, como era o cinema clássico hollywoodiano. Muito do que o cinema hoje tem como característica se deve a este ambiente de transição, ambiente que compreende principalmente os anos 70. Foi com esta constatação que se deu um importante passo novamente a supremacia do cinema americano.

Segundo Costa, são três as características que definem os filmes deste momento de transição e suas propostas de desinstitucionalizaçãa $0^{28}: 1$. o fim de um sistema de produção estruturado sobre o produto médio, mas articulado em vários níveis (filmes de série A e B, filmes de auteur, etc.), que constituía um quadro de referência também para o cinema moderno; 2. a desarticulação e a desagregação da produção, razões pelas quais os filmes individuais (do supercolosso ao filme marginal) que têm identidade própria; 3. queda da capacidade do cinema de reunir um público mais vasto e heterogêneo, donde se desenvolve uma forma de fruição fragmentada e dispersa: a especializada (filmes de autor, cult movies nos cineclubes, filmes para jovens, filmes 'no feminino', filmes pornográficos etc.) e a 'distraída', dos filmes de televisão. ${ }^{29}$

Ainda segundo Costa, eram dez os "mandamentos" destes novos diretores: 1. produções de pequeno orçamento; 2. pequenos orçamentos produtivos; 3. busca de um público jovem; 4. discussão dos valores éticossociais sustentados pelo cinema precedente; 5 . atenção à política e aos costumes; 6 . construção de estilemas de caráter documentarista; 7.renúncia aos estúdios e procura dos espaços cotidianos; 8. mudança dos diretores

\footnotetext{
${ }^{24}$ COSTA, Antonio. Compreender o cinema. São Paulo: Globo, 2003. Pág. 121.

${ }^{25}$ Id. Ibid. Pág. 120.

${ }^{26}$ Id. Ibid. Pág. 132.

${ }^{27}$ SKLAR, Robert. História social do cinema americano. São Paulo: Ed. Cultrix, 1975. Pág. 353.

${ }^{28}$ Ainda segundo Costa este conceito foi elaborado por Casseti. COSTA, Antonio. Compreender o cinema. São Paulo: Globo, 2003. Pág. 133.

${ }^{29}$ Id. Ibid. Pág. 134.
} 
dominantes; 9. abandono do star system; 10. revisão ideológica dos "gêneros clássicos". Estas normas demonstram claramente a identificação destes com a nouvelle vague cinematográfica francesa e sua política de auteur. Entretanto, seus traços transparecem também que estes têm uma relação não tão radical em relação ao sistema hollywoodiano, mais focalizado em uma revisão crítica deste do que um niilismo elaborado.

Estes novos diretores holywoodianos, aliados as grandes empresas de produção e distribuição, as majors, foram capazes não somente de retomar a supremacia do cinema americano, como também foram capazes de enraizar as novas características que seriam à base do cinema norte-americano, seu alicerce, sua identidade nos dias de hoje.

\section{O Clube dos Cinco, um estudo de caso.}

- 3.1. Apresentação de ficha técnica resumida;

Título em português: O Clube dos Cinco.

Título Original: The Breakfast Club.

Gênero: Drama;

Tempo de Duração: 93 minutos;

Ano de Lançamento (EUA): 1985;

Classificação americana: $\mathrm{M}^{30}$;

Estúdio: Universal Pictures / A\&M Films;

Distribuição: Universal Pictures;

Elenco: Emilio Estevez (Andrew Clark), Anthony Michael Hall (Brian Johnson), Judd Nelson (John Bender), Molly

Ringwald (Claire Standish), Ally Sheedy (Allison Reynolds);

Direção: John Hughes;

Roteiro: John Hughes;

Produção: John Hughes e Ned Tanen;

Música: Wang Chung, Keith Forsey e Simple Minds;

- $\quad$ 3.1.1 Contexto do filme e das pessoas envolvidas.

Antes de se começar a se fazer uma análise fílmica da obra é necessário que se faça um breve histórico dos personagens que o compõe. Dentre os principais responsáveis pela realização deste filme, John Hughes foi sem dúvida aquele que mais teve participação no processo de pré-produção. Hughes, além de diretor e produtor do filme, foi também roteirista e ator coadjuvante. Nascido em 1950, Hughes começa a trabalhar como escritor da National Lampoon's Magazine. Segundo consta, Hughes, tal como os cineastas da nouvelle vague francesa, começou a exercer o ofício de diretor para poder ter um controle real do processo em que seus roteiros seriam filmados.

Quanto aos protagonistas, eles representavam a juventude dos anos 80 e, apesar de cada um ter uma história relativamente diferente, eles estavam lá pelo mesmo motivo, para exercer a identificação dos jovens da época para com seus personagens, o que tornava cada um deles ícones visuais, aonde o princípio da aura, elaborado por W. Benjamin, tinha reflexo quase que imediato ${ }^{31}$.

\section{- $\quad$ 3.1.2. Resenha;}

Em virtude de terem cometido pequenos delitos, cinco adolescentes são confinados na biblioteca de seu colégio em um sábado, tendo de escrever uma redação de mil palavras sobre o que eles pensam de si mesmos. Apesar de serem pessoas bem diferentes, e de início não terem nenhuma afeição entre si, enquanto o dia transcorre passam a aceitar uns aos outros e começam a encontrar semelhanças em suas personalidades.

\footnotetext{
30 "Uma das primeiras tarefas de Valenti foi verificar o que se poderia fazer em relação ao código. (...) Colocou em seu lugar um sistema de classificação semelhante ao modelo da Grã-Bretanha (...): G para assistência geral, M para assistência maduras; R para assistência restrita, em que não se admitiam a entrada de menores de dezessete anos a não ser acompanhados de um pai ou responsável, e X que proibia, pura e simplesmente, a entrada de qualquer pessoa com menos de dezoito anos.” SKLAR, Robert. História social do cinema americano. São Paulo: Ed. Cultrix, 1975. Pág. 345.

31 “Ao fazer dos atores pessoas amadas e distantes, recolocou o solo propício para o ressurgimento da aura.” In.: BONASSA, Elvis César. Não chore, é apenas um filme. In: Imagem. Campinas: Ed. Unicamp, n. 5, Ago/Dez, 1995. Pág. 103.
} 
Já no começo do filme, Hughes nos bombardeia com informações. A primeira é de seus referencias musicais; já no primeiro instante do filme, ainda com as legendas anunciando quem foi seu produtor, os atores, etc, se escuta ao fundo a música tema do filme, Don't You Forget About Me, interpretada pelo grupo Simple Minds. É interessante notar que esta banda tem uma forte identificação com a juventude americana dos anos oitenta.

Para trazer ainda mais à tona esta identificação do filme com a juventude dos oitenta, logo ao fim dos créditos iniciais surge um escrito com um fundo negro. Neste texto, escrito por David Bowie, os espectadores são alertados com quem nós devemos nos identificar, com os adolescentes, e a quem este filme não vai interessar, aos "inimigos", os adultos ${ }^{32}$.

Na cena posterior a esta, nos é apresentado o colégio. Esta cena é interessante por um aspecto, principalmente. Em um dado momento, aparece a foto do Man of the year, e, em uma das fotos, aparece a imagem de um jovem, este rapaz é o faxineiro do colégio. Talvez esta imagem seja representativa, demonstra a forma patética em que os adultos vão representados durante todo filme.

É também interessante notar que ao fundo desta cena é possível escutar a voz de um dos personagens dizendo parte das frases que vão finalizar o filme. Neste instante do filme estas frases têm a função de expor qual vai ser um dos problemas principais do filme, o da visão do adolescente em relação a ele e ao outro.

Na seqüência seguinte, nos é mostrado outro tema central do filme, a relação do adolescente com seus pais. Ao despedirem-se de seus pais todos demonstram algum tipo de relação problemática, ainda que seja na forma da ausência dos pais, como é o caso de Bender, personagem vivido por Judd Nelson.

A cena que vem logo após esta demonstra quem são os personagens, dentro de seus estereótipos. A princess é a primeira a chegar, logo após ela chegam Brian (the brain), e Andrew (the athleth), seguidos por John Bender (the criminal) e Allison (the basket case). O engraçado é que nos momentos que se seguem, os personagens são exatamente aquilo que se esperaria deles, ou seja, correspondem exatamente ao que se espera deles.

Esta apresentação da estereotipía dura até o momento em que o diretor chega. Com ele na sala, ao que parece, acaba acontecendo uma união pelo bem comum, e assim será pelo resto do filme, uma espécie de "nós contra eles”. Este diretor, Senhor Vernon, lhes dá uma tarefa para ser feita até o final do dia: uma redação contendo mil palavras dizendo "who you think you are".

Todos tentam da melhor forma fazer o tempo passar, entretanto, a única forma que foi possível encontrar foi a da interação entre eles. Neste momento, mais um mistério é revelado, de que forma se dá a relação entre Claire e seus pais. Para ela, seus pais a usam para irritar um ao outro e ela sente que eles não gostam dela. A dinâmica do filme também se revela, serão estas as motivações para que se acompanhe o filme, saber o que cada um fez para estar em detenção e como cada um deles lida com a relação que tem com seus pais.

Para Aberastury, a adolescência em seu transcorrer é caracterizada por uma fase de desprendimento interno dos pais, possibilitado pela maturação biológica que coloca o adolescente em pé de igualdade, de certa forma, de assumir os mesmos papéis e formas de satisfação que os pais. Passa a ser um potencial procriador. Por outro lado, com a possibilidade real do incesto, advinda deste amadurecimento, é gerado um momento de confusão e de contradições, caracterizado por conflitos com o meio familiar. Ou seja, a adolescência acaba por se tornar um momento em que existe uma reestruturação das relações até então estabelecidas. Mesmo porque é também na adolescência que se percebe que o "gozo" que estava para ela prometido, retratado pelo Complexo de Édipo, nunca será seu.

A primeira alienação para o sujeito é a que ele aceita quando alguém lhe diz: “quando você crescer”. Portanto, para a criança, de alguma maneira, crescer é o projeto proposto. Na adolescência, a constatação de que esta promessa era enganadora se impõe. O gozar orienta o supereu na trilha do interdito, e constatamos que essa ordem de gozo do supereu é uma injunção que encontra o impossível, e não só uma interdição, uma proibição. ${ }^{33}$

\footnotetext{
${ }^{32}$ Na versão original o texto se encontrava desta forma: "And these children; that you spit on; as they try to change their world; are immune to your consultations; they're quite aware; of what they're going through".

${ }_{33}$ RASSIAL, Jean-Jacques. Adolescência como conceito da teoria psicanalítica. In: O adolescente e o psicanalista. Rio de Janeiro: Companhia de Freud, 1999. Pág 47.
} 
Parece-me que J. Hughes estava a par dos estereótipos dos adolescentes e seus problemas para com seus pais. Esta vertente da história ira perdurar até os momentos finais do filme.

Já na seqüência, o personagem Bender pergunta a Andrew como este se dava com seus pais. O dialogo deles é interessante e merece ser transcrito:

Bender: Sporto?

Andrew: que?

Bender: você se dá bem com teus pais?

Andrew: Se eu disser que sim, sou um idiota, não é?

Bender: É idiota de qualquer modo. Se dissesse que se dava bem seria mentiroso também.

Em cena seguinte se chega a outra conclusão, como se dão às relações entre John e seus pais. Em uma cena interessante ele nos retrata como seria um diálogo entre ele e seus pais:

Bender (imitando o pai): Estúpido, inútil, não presta pra nada, seu sacana! Retardado, boca suja, burro, imbecil!

Bender (imitando a mãe): Esqueceu feio, preguiçoso e malcriado.

Bender (imitando o pai e fazendo um movimento de agressão a mãe): Cala a boca! Vai buscar uma empada de peru.

Bender (fazendo ele mesmo): E você pai?

Bender (imitando o pai): Dane-se.

Bender (fazendo ele mesmo): E você pai?

Bender (imitando o pai): Dane-se.

Bender (fazendo ele mesmo): Não pai, e você?

Bender (imitando o pai): Dane-se (fazendo o movimeto como se eles estivassem se agredindo)

Brian: É mesmo assim?

Bender: quer ir lá em casa um dia?

Andrew: Faz parte da tua imagem. Não acredito.

Bender: Não acredita?

Andrew: Não.

Bender: Não?

Andrew: Eu gaguejei?

Bender (indo em direção a Andrew): Acredita nisto? (mostra o braço); É do tamanho de um charuto. Gaguejei?

Na cena seguinte todos se aproveitam do fato do diretor Vernon ter saído de sua sala e vão "passear" nos corredores do colégio. Nesta cena o tema das drogas passa a ser revisto. Em uma cena mais adiante ela age como um verdadeiro agente sociabilizante e faz com que os estudantes deixem suas barreiras caírem e tenham uma relação mais próxima. Este papel também vai ser desempenhado pela música ${ }^{34}$.

O interessante é que no momento em que estes estão voltando para a sala da biblioteca, eles percebem que tem pouco tempo e que podem dar de cara com o diretor a qualquer momento. Esta cena é interessante apenas por um aspecto, ela tem uma estética característica de desenhos animados. Parece-me muito com as cenas de perseguição de Scooby Doo.

Apesar dos esforços, os alunos chegam um lugar sem saída. Neste instante Bender toma si para a culpa dos atos e sai pelos corredores desviando a atenção do diretor para que os outros consigam chegar a biblioteca. Esta atitude tem relação direta com o "mito do herói”, estudado por Campbell, segundo este, o sacrifício é o que realmente torna alguém o herói, "é comum que as pessoas pensem no Herói em termos de força ou coragem, mas essas qualidades são secundárias em relação à capacidade de sacrifício - esta, sim, a verdadeira marca do Herói”. ${ }^{35}$

Após ser pego pelo diretor, Bender é separado do grupo e ameaçado pelo diretor. Esta cena tem o propósito de deixar claro a relação que a sociedade tem com os jovens. Em seu discurso, o senhor Vernon diz a Bender que ninguém acreditará nele, e que seria a sua palavra contra a dele, e que a do diretor tinha muito mais peso.

Bender, utilizando-se do forro do teto, consegue voltar para a biblioteca sem que seja notado pelo diretor. Pega a droga que havia deixado com Brian, e neste momento a droga assume uma postura sociabilizante. Parece

\footnotetext{
34 “Quanto da paixão por um som ou imagem hoje se baseia em associação: não porque a música seja admirável, mas porque ‘esta é a nossa música’? Não podemos dizer.” HOBSBAWN, Eric J. Era dos Extremos: o breve século XX (1914-1991). São Paulo: Companhia das Letras, 1995. Pág. 503.

${ }^{35}$ VOGLER, Christopher. A Jornada do Escritor: Estruturas míticas para contadores de histórias e roteiristas. Rio da Janeiro: Ampersand Ed., 1997. pág. 57.
} 
mesmo que as mascaras caem. É também neste instante que outros assuntos delicados é tratado, a relação de Allison com seus pais, que a ignoram.

As cenas posteriores são as mais instigantes do filme. Nesta cena, o diretor Vernon e o faxineiro Carl conversam no porão. Nesta conversa, Vernon se indaga como foi que os jovens ficaram tão piores do que os de antigamente, no que Carl responde: "não foram eles que mudaram foi você que mudou". Vernon desempenha o papel do que Allison mais tarde vai decretar que seja o mal dos adultos, ela diz: "quando nós ficamos velhos nosso coração morre”. Este é o papel de Vernon nesta história, o do adulto em que seu coração morreu. Carl, por sua vez, desempenha o papel do adulto menos patético e que, por conta disto, tem uma relação mais sadia com os adolescentes.

Quanto à cena seguinte, a "cena da roda”, ela precisará de uma transcrição quase completa, pois se trata da mais importante cena do filme.

Andrew: O que eu faria por um milhão de dólares? O mínimo possível.

Claire: é monótono.

Andrew: que querem que eu diga?

Claire: tem que pesquisar a mente em busca do limite absoluto. Como... seria capaz de ir nu para a escola?

Andrew: teria que sair do carro?

Claire: claro

Andrew: na primavera ou inverno?

Claire: primavera.

Andrew: na frente ou atrás da escola?

Claire: tanto faz.

Andrew: sim.

Allison: Eu seria capaz. Faço qualquer coisa sexual. E sem um milhão de dólares.

Claire: está mentindo.

Allison: já o fiz. Já fiz quase tudo, exceto certas coisas ilegais. Sou uma ninfomaníaca.

Claire: mentira.

Brian: teus pais sabem disto?

Allison: só disse ao meu psiquiatra.

Andrew: e que foi que ele fez?

Allison: meteu em mim.

Claire: muito simpático.

Allison: não acho que do ponto de vista legal, ele tenha me violado pois eu paguei.

Claire: ele é adulto!

Allison: E casado.

Claire: não entende como isto é indecente?

Allison: as primeiras vezes...

Claire: Primeiras vezes?! Ele fez mais de do que uma vez?

Allison: Sim

Claire: é doida?

Brian: ela transa com o psiquiatra.

Allison: já fez alguma vez? (perguntando para Claire)

Claire: nem sequer tenho um psiquiatra.

Allison: Mas já vez com alguma pessoa normal?

Claire: Já não falamos sobre isto?

Bender: Você nunca respondeu a pergunta.

Claire: Não falo da minha vida particular com desconhecidos.

Allison: é uma faca de dois gumes, não é?

Claire: o que?

Allison: se disser que nunca o fez é uma puritana. Se disser que fez é uma sórdida. Não há saída. Quer, e não pode. E quando faz deseja não ter feito.

(...)

Bender: se responder a pergunta.

Todos fazem pressão para ela responder a pergunta.

Claire: Nunca fiz!

Allison: Eu também não. Não sou uma ninfomaníaca, sou uma mentirosa compulsiva. 
O tema da sexualidade nos é mostrado como um tabu, e ao mesmo tempo algo muito próximo, tal como nos foi elucidado pelo texto da psicanalista Arminda Aberastury.

A seqüência desta cena é bem interessante, pois é quando eles descobrem que, ao menos uma coisa une a todos, a estranheza. Todos têm as suas peculiaridades. E quem agora vai apresentar a sua, é o personagem de Estevez. Andrew nos conta o motivo de estar em detenção, ele havia colado com fita adesiva as nádegas de um garoto peludo. Durante esta cena, ele não somente nos conta como o fez, mas também o que motivou seu ato, a expectativa do seu pai. "Andrew, você tem que vencer, vencer, vencer. Nós não aceitamos perdedores nesta família”. Ele não consegue suportar a expectativa que os outros tem em relação a ele, principalmente seu pai. E o pior de tudo, não concorda com os próprios atos, os enxerga de forma bastante pejorativa e brutal. "como alguém pode perdoar uma atitude destas”, pergunta aos outro sobre si mesmo.

É também nesta cena, que Brian começa a desvendar, para nós, as suas motivações e como se davam as suas relações com seus pais. Ele diz que também sofre com a pressão da expectativa que se criou em relação as suas notas e seu desempenho.

Então um tema incomodo surge, Brian pergunta como será a relação deles amanhã, diante do convívio social normal, com seus grupos e pares. Claire responde que as relações irão continuar as mesmas de antes daquele dia, ou seja, cada um cumpriria seu estereótipo, e se relacionaria apenas com seus "iguais". Após uma intensa discussão, Claire diz que Brian e Allison não sabem o que é “ter que fazer tudo o que meus amigos querem”, alusão a expectativa criada em relação a ela e a Andrew.

Esta fala desperta a raiva de Brian, que finalmente conta o motivo de sua punição, ele havia escondido uma arma, um sinalizador, em seu armário e este explodiu. Conta também que não estava conseguindo atender as suas expectativas, e de seus pais, em relação a uma matéria, que ele tiraria uma nota ruim. Ele não estava preparado para uma nota baixa, e nem seus pais. Pensou em cometer o suicídio, e por estes motivo a arma estava em seu armário. E, para acabar com a cena, e também com o clima tenso desta, Allison nos conta o motivo dela estar na detenção, segundo ela, "por nada. Não tinha nada para fazer”. Não fica claro se ela está apenas cumprindo seu papel de estranha, de "caso perdido", ou se ela havia ido cumprir detenção apenas para chamar a atenção de seus pais, motivo que também a fazia andar durante todo o filme pegando coisas dos outros e colocando em sua bolsa.

Esta cena praticamente desvenda todo o filme, já sabemos os porquês de cada um estar em detenção e já se sabe sob que dinâmica se dá à relação destes com seus pais.

O que falta é somente o desfecho tradicional do cinema americano, a formação dos casais. O que é prontamente atendido pela "inesperada" conciliação entre Bender e Claire, e Allison e Andrew. Enquanto isto, Brian, o cérebro, fica responsável por redigir uma redação que todos iriam apresentar como um grupo. Esta é a versão original, e mais interessante:

"Dear Mr. Vernon,

We accept the fact that we had to sacrifice a whole saturday for whatever it was you thought we did wrong, but we think you're crazy to make us write an essay on who we think we are. You see us as you want to see us, in the simpliest terms and the most convenient definitions. But what we found out is that each one of us is a brain, an athlete, a basket case, a princess \& a criminal. Does that answer your question?

Sincerely yours,

The Breakfast Club"

Esta é a carta, e a narrativa, que encerra o filme. Entretanto, o que o filme trás de interessante se encontra na quebra de um paradigma juvenil, o da identificação a partir do grupo, ao menos quebra em relação ao grupo menor, a "tribo", enquanto que se abre para um grupo de identificação maior, o jovem. Este filme me lembra muito uma música do grupo The Who, a música, intitulada My Generation, tem a seguinte frase: "I hope I'll die before I get old”. Para gerações sucessivas de jovens, a única proposta que era posta para eles era a de ser jovem. Era isto os identificava, era isto que os fazia alguém, e era também até aonde sua imaginação conseguia ir.

E é isto que este filme é, uma ode a esta geração, e também as que a precedem, ao menos até estas terem se tornado seus pais.

Já do ponto de vista técnico, o filme tem poucos momento de arrojo, mais precisamente dois, um mais recorrente, que é o das tomadas longas com diálogos que não são cortados por mudança de planos, algo que lembra Goddard. Já o segundo, diz respeito também a cena da rodinha, entretanto, é mais relacionado a visão exterior do que a forma que os cortes se dão. Nesta cena, a câmera faz o nosso papel no filme, nos deixa muito próximos de sermos parte do grupo, e de tão próxima, em dados momentos ela tira de foco alguns personagens. Hughes abusa do 
movimento de plano-contraplano da câmera e realmente não "inventa" nada de novo em relação à linguagem expressiva clássica.

É interessante notar que este filme reza quase que integralmente pela cartilha dos filmes de auteur dos cineastas dos anos 70 e 80. Dos dez mandamentos elencados por COSTA que podiam ser consideradas as características destes cineastas pós-modernos poucos não foram seguidos.

\section{Consideraç̧̃es Finais:}

Segundo Edgar Morin, motivado pela crise do cinema americano e o sucesso do cinema europeu em território norte-americano, Hollywood tomou para si um modelo que contemplava os dois tipos de cinema, um que primava pelo espetacular ${ }^{36}$, enquanto que o outro primava por outros aspectos, tal como roteiros elaborados e apreciação dos críticos. Entretanto, "esses dois cinemas não são porém impermeáveis um ao outro. São dois sistemas acoplados, siameses, e entre eles existe circulação, contaminação, conflito e cooperação",37.

É isto que este filme nos demonstra que é, um "siamês", um amalgama entre estes dois, entretanto, não possui nem o orçamento do primeiro e tampouco a credibilidade do segundo. Trata-se por natureza de um marginal, algo bem comum a esta cultura juvenil, algo mesmo coerente com esta.

Percebe-se portanto, que este "primo pobre", e pouco nobre, destes tem sim muito em comum com eles, e portanto chega quase a ser um absurdo que seja relegado a apenas um desvio de pessoas mal intencionadas em relação a arte. Isto também nos é lembrado por Christian Metz, e é com sua frase que se encerra este artigo: "Pois esse filme no qual eu penso possui uma forte existência (social, analítica). Não se poderia reduzi-lo a um gadget de certos produtores de cinema ávidos por dinheiro e mal-intencionados a obtê-los. ${ }^{\text {33 }}$

\section{Referências bibliográficas.}

ABERASTURY, Arminda; KNOBEL, Mauricio. Adolescência normal: um enfoque psicanalítico. Porto Alegre: Artmed, 2000.

ADORNO, Theodor W. Textos Escolhidos. In.: Coleção os Pensadores. São Paulo: Ed. Nova Cultural Ltda, 1999.

BONASSA, Elvis César. Não chore, é apenas um filme. In: Imagem. Campinas: Ed. Unicamp, n. 5, Ago/Dez, 1995.

CANEVACCI, Massimo. Antropologia do cinema: do mito à industria cultural. São Paulo: Brasiliense, 1984.

COSTA, Antonio. Compreender o cinema. São Paulo: Globo, 2003.

FEATHERSTONE, Mike. Cultura de consumo e Pós-modernidade. São Paulo: Studio Nobel, 1995.

FREUD, Sigmund. A dissolução do complexo de Édipo. In: Obras Completas. Rio de Janeiro: Imago, 1974.

GANS, Herbert J. Popular Culture and High Culture: an analisys an evaluation of taste. New York: Basic Books, 1974.

HOBSBAWN, Eric J. Era dos Extremos: o breve século XX (1914-1991). São Paulo: Companhia das Letras, 1995.

JAMESON, Frederic. Pós-Modernismo: A lógica cultural do capitalismo tardio. São Paulo: Editora Ática, 1997.

\footnotetext{
${ }^{36}$ Tratava-se do que ele chama de “evasivo-espetacular” MORIN, Edgar. As Estrelas: Mito e Sedução no cinema. Rio de Janeiro: José Olympio, 1989.

${ }^{37}$ Id. Ibid. Pág. 125.

${ }^{38}$ METZ, Christian. Historia/ Discurso (notas sobre dois voyeurismos). In: XAVIER, Ismail (Org.). A experiência do cinema: antologia. Rio de Janeiro: Editora Graal, 1983. Pág. 405.
} 
JAMESON, Frederic. Pós-modernidade e sociedade de consumo. In: Novos Estudos, Cebrap, n. 12, São Paulo, junho 1985.

MORIN, Edgar. As Estrelas: Mito e sedução no cinema. Rio de Janeiro: José Olympio, 1989.

RAMOS, José Mario Ortiz. Televisão, Publicidade e cultura de massa. Petrópolis: Vozes, 1995.

RASSIAL, Jean-Jacques. Adolescência como conceito da teoria psicanalítica. In: O adolescente e o psicanalista. Rio de Janeiro: Companhia de Freud, 1999.

SKLAR, Robert. História social do cinema americano. São Paulo: Ed. Cultrix, 1975.

VANOYE, Francis; GOLIOT-LÉTÉ, Anne. Ensaio sobre a análise fílmica. Rio de Janeiro: Papirus, 1994.

VOGLER, Christopher. A Jornada do Escritor: Estruturas míticas para contadores de histórias e roteiristas. Rio da Janeiro: Ampersand Ed., 1997.

XAVIER, Ismail. Parábolas cristãs no tempo das imagens. In: Imagem. Campinas: Ed. Unicamp, n. 5, Ago/Dez, 1995.

XAVIER, Ismail (Org.). A experiência do cinema: antologia. Rio de Janeiro: Editora Graal, 1983. 